\title{
Wiki-based Collaborative Writing: A Comparative Study on First and Second Language Writing among Chinese Secondary Students
}

\author{
Samuel K. W. Chu \\ Faculty of Education, The University of Hong Kong, Hong Kong \\ Email: samchu@hku.hk
}

\author{
Jing Wu \\ National Institute of Education, Nanyang Technological University, Singapore \\ Email: NIE152066@e.ntu.edu.sg \\ Crystal W. S. Kwan \\ City University of Hong Kong, Hong Kong \\ Email: clemencecrystalkwan@gmail.com \\ Jean H. Y. Lai \\ Hong Kong Baptist University, Hong Kong \\ Email: jeanlai@comp.hkbu.edu.hk
}

Received: 08 October 2018; Accepted: 27 October 2018; Published: 08 January 2019

\begin{abstract}
This study aims to examine how learners engaged in wiki-based collaborative writing when they were using their first language (L1) or second language (L2). Issues concerning similarities and differences in wiki collaborative writing activities, wiki participation levels, wiki interaction patterns and wiki collaboration levels between the L1 and L2 writing groups are discussed. This paper reports a case study of a group of Hong Kong secondary school students who were required to use "Google Sites" to complete their Liberal Studies group projects. Student's wiki writings and comments in their L1 (Chinese) and L2 (English) were collected and examined. Results indicated that, while similarities in writing activity patterns, participation levels and collaboration levels were shown in the two groups, differences did exist in their interaction patterns, which were affected by the different ways they used the wiki comment sections. This study can help educators to become aware of the different needs of L1 and L2 groups and to implement wiki collaborative writing more effectively to support students.
\end{abstract}

Index Terms-Wiki, Collaborative writing, First language writing, Second language writing

\section{INTRODUCTION}

Effective writing skills are important as they help one to meet academic and employment requirements. With emerging technology, people's writing modes are changing from paper and pen to computer word processors and then to online writing tools like the wiki. These changes have attracted the attention of researchers. Specifically, research studies on wiki-based collaborative writing have grown over the last decade [1, 2, 3]. However, while it is agreed that wiki-based collaborative writing contributes to language learning, few of these studies have paid attention to wiki-based L2 writing and how it differs from L1 writing. Thus, this study aims to provide an understanding of how students participate in wiki writing activities, how they interact and collaborate with one another, and whether any similarities and differences exist between L1 and L2 writing groups. It aims to increase the awareness of the different needs of L1 and L2 writing groups and to contribute to the current design and practice of wiki collaborative writing.

\section{LITERATURE REVIEW}

In this section, we first review wiki-based collaborative writing. Following this, we review studies on L1 and L2 writing, specifically wiki-based L1 and L2 writing. This review helps inform the research questions proposed in the following section.

\section{A. Wiki-based Collaborative Writing}

Collaborative writing refers to the writing process through which documents are created by more than one author [4]. According to Geraci [5], a wiki is an online 
tool "that allows people to contribute, edit, and read content on a particular subject" (p. 3). For the purpose of this study, we examine the following areas of collaborative writing: wiki collaborative writing activities, wiki participation levels, wiki interaction patterns and wiki collaboration levels.

\section{A.1. Wiki collaborative writing activities}

Common activities in wiki-based collaborative writing include co-writing, coediting and commenting. For the purpose of this study, we examine the current literature on co-writing and coediting in this sub-section. It has been observed that students are more likely to add content than to delete existing content when they write collaboratively [3]. Similarly, students have also been found to focus more on the content than on the layout of a website [6] or peers' writing errors [7] in their co-writing process. Storch [8] studied the collaborative writing of university students and found that some participants were not confident in their L2 proficiency and thus avoided correcting group member's writing errors.

\section{A.2. Wiki participation levels}

Wiki participation levels, another important area of wiki-based collaborative writing, may be examined by the frequency of students writing on wiki. In Wheeler, Yeomans and Wheeler's study [9], many of the British undergraduate students wrote on wiki during class hours. However, not many students wrote on wiki frequently outside class. Low participation in wiki collaborative writing was also reported in Ebner, Kickmeier-rust, and Holzinger's study of a group of university students [10]. Moreover, Ebersbach, Glaser and Heigl [11] found in their study that, usually, only one or two British undergraduate students engaged in wiki writing within a group outside class. Such variation in contributing to wiki writing among wiki collaborative writers was also reported in Leung and Chu's study [12].

\section{A.3. Wiki interaction patterns}

Comments are often used to determine interaction patterns as they best captured the dynamic interaction among members in the same group. Comments can be further divided into the three forms: type, area and nature [13]. Bradley's study [14] showed that suggestion was the most frequent type of comment; global comment such as commenting on idea development, audience, purpose and organization of the writing - was the most frequent area; and revision was the most frequent nature of comments. Judd, Kennedy, \& Cropper [15] reported that majority of the comments in their study were directed to the group rather than individuals and that only a few comments were responses to previous comments, indicating unsuccessful attempts to engage peer learners. Researchers have also reported that students seldom comment on the language errors made by their peers [16, 17]. Social concerns of students may account for this [14, 18]. It has also been reported that native speakers tend to write more comments than non-native speakers $[14,19]$.

\section{A.4. Wiki collaboration levels}

Revision on wiki may provide information about the level of wiki collaboration. It has been reported that students tend to avoid editing other group members' writing [7] and that they think they have to obtain approval from peers before they do so [20]. Kessler's study with a group of non-native speaker English teachers [16] also showed that participants tended to focus on meaning rather than on form, with a significant number of them commenting that forms and grammatical errors were minor and unimportant for revision on wiki.

The above review has provided a backdrop for our current study. We now turn to L1 and L2 contexts and examine the less discussed area of comparison between wiki-based collaborative writing in L1 and L2 contexts.

\section{B. Wiki-based L1 and L2 Collaborative Writing}

Researchers have explored the differences between L1 and L2 writing. Silva [21], for example, examined 72 reports comparing L1 and L2 writing, and concluded that L2 writing is more difficult and less effective than L1 writing. Our review shows that most studies on L1 and L2 writings focus on areas such as formulation process [22], revision patterns [23], and discourse organization [24]. There are comparatively fewer studies on collaborative writing, and similarities and differences between L1 and L2 collaborative writing. Similarly, most existing research on technology-enhanced writing has been conducted in L2 settings [25, 26, 27]. Few studies have examined technology-based L1 and L2 collaborative writing, not to mention wiki-based L1 and L2 writing. With regards to the foci of this study, collaborative writing activities and wiki interaction patterns have been examined in some studies [13, 14, 18]. Nevertheless, far fewer studies have examined participation levels and collaboration levels in L1 and L2 wiki-based collaborative writing.

To fill this research gap, this project aimed to identify and compare the writing activities, participation levels, interaction patterns and collaboration levels between L1 and L2 wiki-based collaborative writing among Chinese secondary students. A deeper understanding of wikibased L1 and L2 writing groups will facilitate the more effective implementation of wiki collaborative writing while catering to the needs of the two groups in schools.

\section{MethDOLOGY}

Based on the gaps identified in the literature review, the study aimed to investigate the following research questions:

(1) What are the similarities and differences in wiki collaborative writing activities between the L1 and L2 writing groups?

(2) What are the similarities and differences in wiki participation levels between the L1 and L2 writing groups?

(3) What are the similarities and differences in wiki interaction patterns between the L1 and L2 writing groups? 
(4) What are the similarities and differences in wiki collaboration levels between the L1 and L2 writing groups?

We adopted a case study approach to the current study. In the following paragraphs, we elaborate on the case study approach, and follow this with a report on our participants and our methods of data collection and analysis.

\section{A. Case Study Approach}

This study adopted case study approach, a research method that investigates a case "in depth and within its real-world context" [28]. A case according to Merriam [29] can be "a single instance, phenomenon, or social unit" (p. 21). Examples of a case are a second language learner or a science class [30].

Case study approach was used in the current study for two reasons. Firstly, case study approach, with its indepth investigation, is suitable to understand the "how" and "why" of the instance, phenomenon, or social unit under study. In the current study, a case study approach helped us to address the similarities and differences in the wiki-based learning between the L1 and L2 groups. It was also helpful to explain "how" and "why" of these similarities and differences. Secondly, case studies are often used in the study of first and second language development in applied linguistics [31]. According to Duff [32], case studies provide "very detailed accounts of the processes and/or outcomes of language learning" for a wide span of learners (p. 34). Considering that the participants in the study were L1 and L2 learners, the approach seems ideal for this study. For these two reasons, case study approach was adopted.

Specifically, a multiple case study design was applied in this study, with altogether eight cases comprising four L1 groups and four L2 groups. A multiple case design was adopted for its exploratory nature to investigate wiki collaborative writing activities, participation levels, interaction patterns and collaboration levels between the L1 and L2 groups. As suggested above, the approach is explanatory in nature in investigating and evaluating how students engage in wiki collaborative writing activities when using their L1 and their L2, how much they engage in the activities, how they interact and collaborate with each other in a reallife setting, and why there are such patterns in $\mathrm{L} 1$ and $\mathrm{L} 2$ contexts.

\section{B. Context and Participants}

The context of this study is Liberal Studies projects in a secondary school in Hong Kong. Research participants were Form One students (average age of 12) from the school. English was used in the project as the medium of instruction. Students were required to form groups of four to seven and to complete their group project using the wiki platform, Google Sites.

They were given the options to use either their L1 (Chinese) or their L2 (English) for their project. Overall, there were 33 groups from five classes. Twenty-six groups completed their projects in L2 (English), and seven groups completed their projects in L1(Chinese).

Among the seven groups that used L1 (Chinese), only four groups commented on Google Sites and were thus selected as the analysis data. As student's writings and comments on Google Sites were the main research data for comparison between the Chinese and the English writing groups, we further selected for data analysis four English groups with a similar total number of versions and comments to that of the Chinese groups. These eight groups comprised the eight multiple cases in the current study.

\section{Methods of Data Collection and Analysis}

This section reports on the methods of data collection and data analysis, including the collection of data from writing activities, a taxonomy of wiki actions for data analysis, the collection of data from comments, the classification of comments, and a taxonomy of revisions for data analysis.

\section{C.1. Data collection of writing activities}

The "Revision History" function of Google Sites allowed us to capture the students' entire writing history on the wiki. This function automatically keeps a record of the number of versions, time of edits and the names of editors. It also allows users to view older versions, compare different versions and revert to older versions of the page. By applying the "Revision History" function, we were able to retrieve and compare writing activities.

\section{C.2. Wiki actions taxonomy}

Based on Meishar-Tal and Gorsky's taxonomy of wiki actions [3], we designed a revised taxonomy for the data analysis of wiki actions (Figure 1). Meishar-Tal and Gorsky based on the taxonomy of Pfeil, Zaphiris, and Ang [33] and constructed a taxonomy of wiki actions that featured hierarchical analysis structure and consistency in classification. For the purpose of this study, we removed the initial edit and content categories and combined the lingual category with the wording category of MeisharTal and Gorsky [3] taxonomy to avoid complex hierarchy structure and repetitive categories. We also added a new category, (edit) "On Image/ Video", with sub categories "Image" and "Video", to the taxonomy as some of the students in our study replaced images and videos or added captions to images on the wiki. 


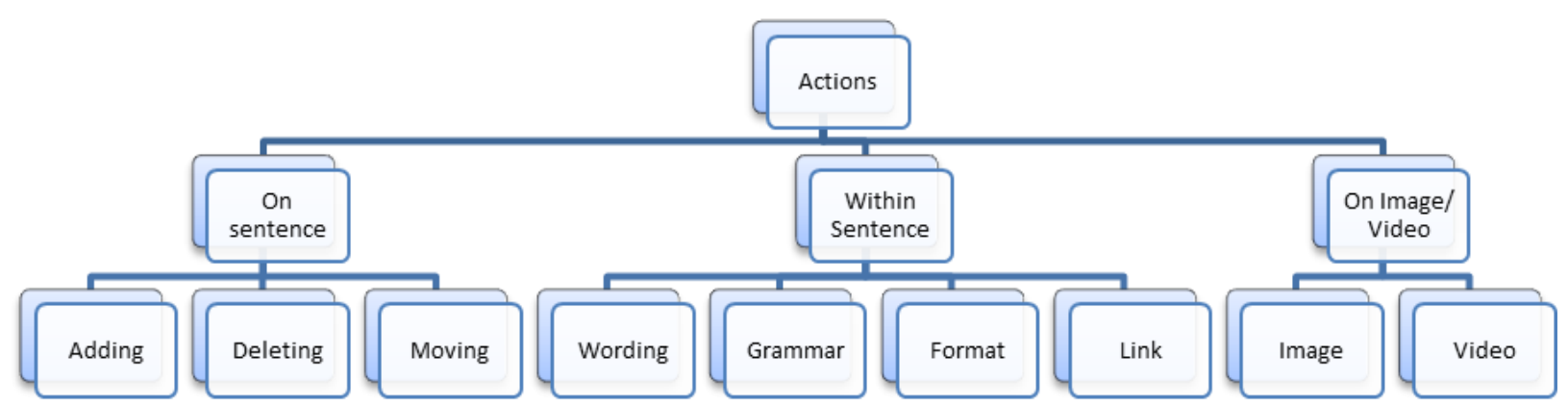

Fig.1. Refined Meishar-Tal and Gorsky (2010) taxonomy of wiki actions

\section{C.3. Data collection of comments and classification of comments}

Table 1. Revised wiki interaction classification based on Curtis and Lawson (2001)

\begin{tabular}{|c|c|c|}
\hline $\begin{array}{l}\text { Interaction } \\
\text { categories }\end{array}$ & Description & Examples \\
\hline Planning & $\begin{array}{l}\text { Organizing work (e.g. } \\
\text { planning group work, } \\
\text { setting shared tasks and } \\
\text { deadlines) } \\
\text { Initiating activities (e.g. } \\
\text { setting up chat sections } \\
\text { to discuss progress or to } \\
\text { organize group work) }\end{array}$ & $\begin{array}{l}\text { "We should } \\
\text { interview } \\
\text { [Name] before } \\
\text { 15th March." } \\
\text { ( L1-G4-Stu A) }\end{array}$ \\
\hline Contributing & $\begin{array}{l}\text { Giving help } \\
\text { Giving feedback } \\
\text { Exchanging resources } \\
\text { and information: } \\
\text { Sharing knowledge } \\
\text { Challenging others } \\
\text { Explaining or } \\
\text { elaborating (e.g. } \\
\text { supporting one's } \\
\text { position when } \\
\text { challenged) }\end{array}$ & $\begin{array}{l}\text { "I agree with } \\
\text { you. I think } \\
\text { parents should } \\
\text { let children deal } \\
\text { with problems } \\
\text { themselves." } \\
\text { (L1-G2-Stu A) }\end{array}$ \\
\hline Seeking Input & $\begin{array}{l}\text { Seeking help } \\
\text { Seeking feedback } \\
\text { Advocating effort (e.g. } \\
\text { urging others to } \\
\text { contribute to group } \\
\text { efforts) }\end{array}$ & $\begin{array}{l}\text { "Are these main } \\
\text { five topics that } \\
\text { we are going to } \\
\text { study?" (L1- } \\
\text { G4-Stu A) }\end{array}$ \\
\hline Monitoring & $\begin{array}{l}\text { Monitoring group effort } \\
\text { (e.g. commenting on } \\
\text { group processes, } \\
\text { achievements, quality of } \\
\text { group work and/or way } \\
\text { of improvement) }\end{array}$ & $\begin{array}{l}\text { I think we } \\
\text { should work } \\
\text { more actively in } \\
\text { order to attract } \\
\text { the teacher's } \\
\text { attention." (L1- } \\
\text { G4-Stu A) }\end{array}$ \\
\hline
\end{tabular}

Google Sites automatically record a comment, the time the comment was posted and the name of the commenter. Thus, we were able to collect all the comment data by reviewing the comment session of each wiki page. All the comments were classified according to a revised classification developed by Curtis and Lawson [1], as shown in Table 1. The original classification includes a category entitled "social interaction" for conversation about social matters not related to the group task. Since wiki project would be the student's final assignment, students might not have wanted their teachers to notice any personal conversations unrelated to the projects; thus, no social interaction comment was found on the wiki. We therefore removed this category of interaction from the wiki interaction classification. In order to have a clear categorization of interaction, we also narrowed down the definition of "planning" and "monitoring" categories to activities related to organizing work and setting up discussion sections for planning and monitoring group contribution respectively.

\section{C.4. Revision taxonomy}

Student collaboration could be reflected by how students reviewed the writing of other group members. To investigate the level of collaboration among the L1 and L2 groups, we applied Arnold, Ducate, and Kost's revision taxonomy [34] to classify the type of edits when there is a change of author in the revision. There are three main categories: meaning developing, meaning preserving and format changing. Meaning developing refers to changes that affect the overall meaning of the text. Meaning preserving refers to changes that paraphrase the ideas in the text but do not change the meaning. Format changing refers to changes that involve copy-editing operations such as spelling, tense, format and others.

For data analysis, the wiki actions and comments were coded based on the wiki actions taxonomy and revision taxonomy. As the wiki actions were quantitative calculations that made much less difference in the analytical process, only one research team member did the coding. With regards to the analysis of wiki comments, two research team members were involved in the coding process of all the wiki comments as they were qualitative data that consisted of more variations. The overall percentage of inter-rater reliability was $81.41 \%$, which illustrated that there were only minor variations in the coding processes. A percentage of over 80 serves as a good reliability check [35].

\section{RESUlTS AND DisCUSSION}

There are five sub-sections in the following paragraphs. Sub-sections 1 to 4 address the above four research questions and discuss areas of wiki-based collaborative writing, namely collaborative writing activities, wiki participation levels, wiki interaction patterns and wiki collaboration levels. Sub-section 5 discusses the implications of the study. 


\section{A. Similarities and Differences in Wiki Collaborative Writing Activities}

Both L1 and L2 writing groups demonstrated similar writing activity patterns, which are shown in Figure 2. The L1 groups performed a total of 1191 edits, and the L2 groups performed 1119 edits on the wikis before the submission deadline of their projects.

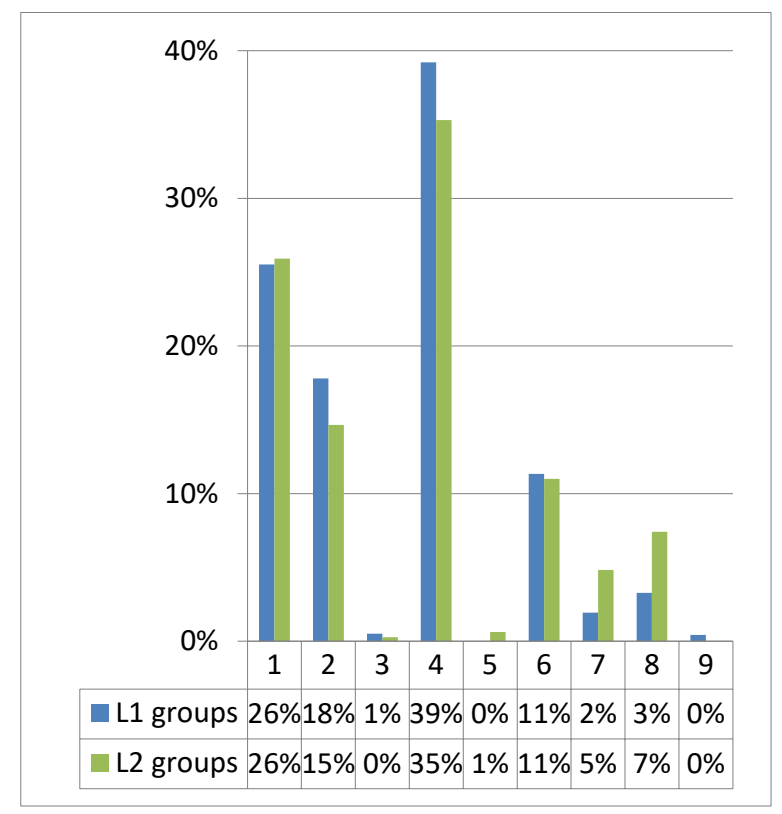

Fig.2. Total Percentage of Wiki Writing Activities in the L1 and L2 Groups(1: adding, 2: deleting, 3: moving, 4: wording,5: grammar, 6: format, 7: link, 8: image, 9: video)

With respect to wiki actions on sentence level, both L1 and L2 groups spent most of their time adding sentences, which constituted $26 \%$ of the total percentage of wiki edits for both groups. Deleting sentences was the second highest activity performed by both groups, constituting $18 \%$ and $15 \%$ respectively of the total percentage of wiki edits. Both groups seldom moved a sentence, with this activity constituting only $1 \%$ and $0 \%$ of the two groups' total percentage of wiki edits respectively. Similar results were also found in Meishar-Tal and Gorsky's study [3], in which students tended to add content rather than delete content when they were writing with others on a wiki.

With regard to wiki actions within sentence level, both groups focused on word edits, which formed 39\% and 35\% of their total percentage of wiki edits. They seldom made any grammar edits with this writing activity, making up $0 \%$ and $1 \%$ respectively of the two groups' total percentage of wiki edits. These results were consistent with Mak and Coniam's study [7] on Hong Kong secondary school student's wiki collaborative writing, in which students seldom corrected one another's writing errors.

Furthermore, both groups focused on content rather than on the website appearance and made few edits related to formatting and adding images. Research by Rick et al. [6] also demonstrated the same pattern in that students focused more on content than on the layout of the website when they were writing collaboratively on wikis. Overall, both L1 and L2 groups showed similar wiki writing patterns.

The nature of this wiki project as a Liberal Studies project may have contributed to the few grammar edits in the two groups. Language accuracy was not the focus of their projects, so they might have paid little attention to grammar revisions. As is suggested by Storch [8], a lack of confidence in language skills might have also hindered the L2 group's motivation to correct grammatical errors because they were using their L2. In contrast, the L1 groups were using their mother tongue to write their reports. As they were familiar with the language, they might have made few grammar errors when they wrote on the wiki. Therefore, the L1 groups might not have needed to make grammar revisions in their writing.

Moreover, the wiki projects would be their final assignments, and teachers would mainly evaluate their performance based on the content rather than on the website appearance. Thus, the two groups tended to review the content more than the look of the website.

\section{B. Similarities and Differences in Wiki Participation Levels}

Wiki writing activity participation levels were reflected by the number of days spent on wiki editing, and both the L1 group and the L2 group showed low levels of participation. The mean number of days spent on wiki writing activities by the $\mathrm{L} 1$ and $\mathrm{L} 2$ groups were 24.5 days and 28 days respectively. Within the five months writing period, both groups spent less than one month on wiki writing activities on average. Furthermore, most of their writing activities were completed in February and March, just two months before they had to submit their projects. These activities formed $84 \%$ and $71 \%$ of the total percentage of wiki writing activities by the L1 and L2 groups respectively, as illustrated in Figure 3. There was a noticeable increase in wiki writing activities from February to March, with both groups completing over 50\% of their wiki writing activities in March.

In addition, since the L1 and L2 groups started their projects at a late stage, both groups performed poorly in information search, which was revealed in the literature review part of their wiki projects. Most groups completed the literature review part of their projects by simply posting a few links and articles from websites and newspapers without summarizing or analyzing the contents

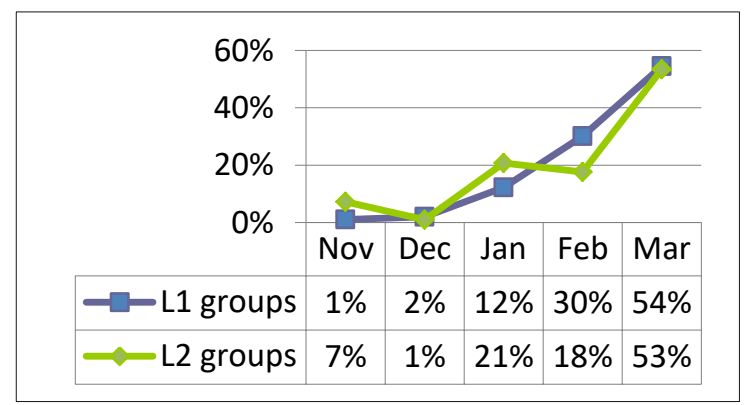

Fig.3. Total Percentage of Monthly Wiki Writing Activities in the L1 and L2 Groups 
The level of participation of both L1 and L2 groups was low at the group level, and we looked further into the individual participation in the two groups. As shown in Figure 4, the L1 group students spent a total of 162 days on wiki writing activities, with a mean and standard deviation of 8 and 6.18 respectively. The L2 group students spent a total of 153 days on wiki writing activities, with a mean and standard deviation of 7 and 7.23 respectively. The standard deviation of the L2 groups was higher than that of the L1 groups, indicating the days spent on wiki writing activities were more varied in the L2 groups than in the L1 groups.

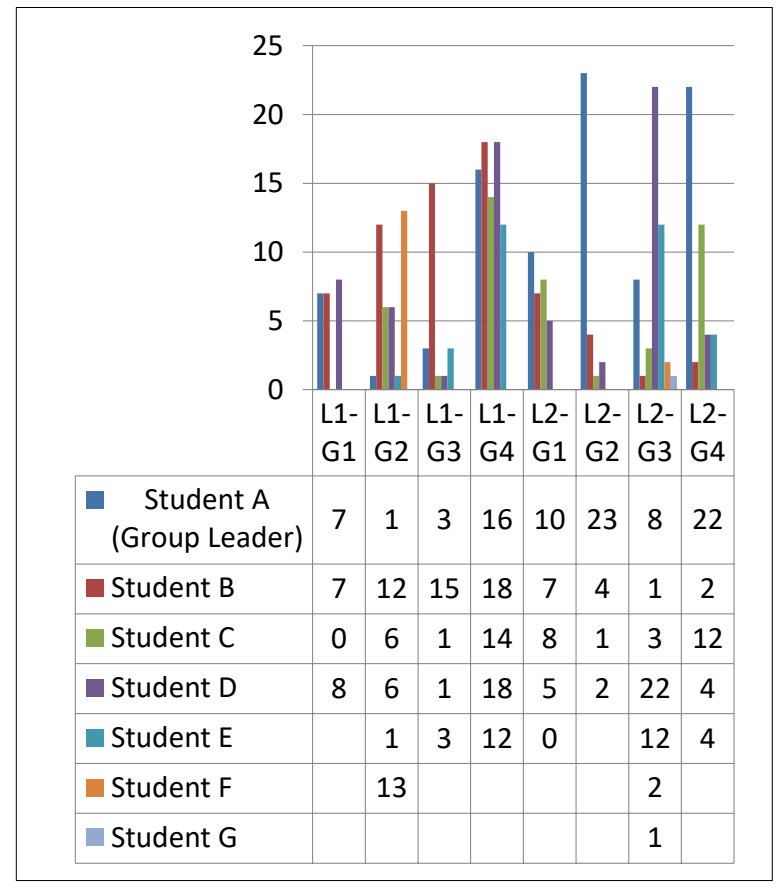

Fig.4. Total Number of Days Spent on Wiki Writing Activities by the L1 and L2 Groups

The number of wiki writing activities performed by students also varied between the L1 and L2 groups. For the L1 groups, the mean and standard deviation of the number of wiki writing activities performed by individual group members was 60 and 54.79 respectively. For the L2 groups, the mean and standard deviation of wiki writing activities performed by individual group members was 53 and 70.87 respectively. The standard deviation of the L2 groups was higher than that of the L1 groups, indicating that the number of wiki writing activities were more varied in the $\mathrm{L} 2$ groups than in the L1 groups.

Although the L2 groups' individual participation was more varied than that of the L1 groups, both groups showed uneven participation levels, which are illustrated in Figure 5. The wiki project contributions were mainly dominated by a few students, with many students making few or no contributions to the wiki. Of the four L1 groups and the four L2 groups, there were two L1 groups and three L2 groups with one student contributing over 50\% of the group's wiki edits.

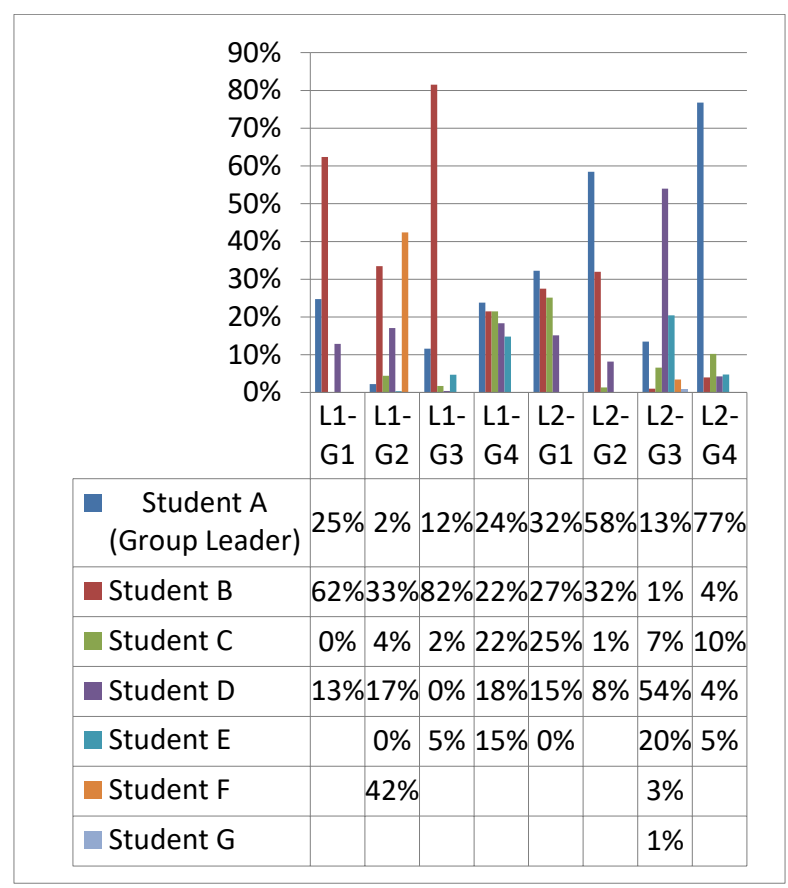

Fig.5. Total Percentage of Wiki Activities Performed by Individual Group Members among the L1 and L2 Groups

Overall, the participation levels of the L1 and L2 groups were low at the group and individual levels, but variation was found with individual group members. The low participation level in wiki collaborative writing found in the present study was consistent with the finding of Ebner, Kickmeier-rust, and Holzinger [10] in their study involving university students. Variation in contributions among wiki collaborative writers have also been identified in previous research [11, 12].

The low participation rates and the variation in contributions among the participants might have been due to a lack of time for planning and writing on the wiki. As illustrated in Figure 3, there was a great increase in wiki writing activities from February to March for both L2 and L1 groups, which implied that the students completed their projects according to a tight schedule. Thus, they might not have had enough time to discuss work allocation and contributions to the wiki. Furthermore, it was possible that the students completed some of their work outside the wiki platform and thus, we could not track these contributions.

Lastly, we noticed that student E in Group 1 of the L2 group used another group member's wiki account when performing the wiki writing task, as shown by student $\mathrm{D}$ in Group 5 posting the following comment on their wiki:

[name of student E], can you use your own account and don't post your reflections in comment...

The individual contribution of the student who borrowed the wiki account would not be captured by the wiki, while the contribution of the student who lent the account would be overstated. Thus, sharing of wiki accounts might also have contributed to the uneven work distribution in the studies. 


\section{Similarities and Differences in Wiki Interaction Patterns}

For wiki interaction patterns, we referred to the comments as they best captured the dynamic interaction among members in the same group. The interaction patterns of the L1 and L2 groups are shown in Figure 6. Most of the comments made by the L1 and L2 groups were related to "contributing" as both groups used the comment session to exchange useful information. The total numbers of "monitoring" comments were similar between the L1 and L2 groups. This contrasts with the previous studies [14, 19], which reported that native speakers tended to write more comments than non-native speakers. A closer examination of the comments made by these groups showed that there were differences in the "planning" and "seeking input" comments between the L1 and L2 groups. Over $20 \%$ of the comments made by the L1 groups were related to planning, as opposed to only $14 \%$ of the L2 groups. Uneven contributions [11, 12$]$ between the L1 and L2 groups may explain this finding. As is shown in Figure 5, over 50\% of wiki edits were completed by one student in each of three L2 groups (L2G2. L2-G3, and L2-G4). Therefore, these groups might have spent less time discussing the project planning as the writing was largely done by one student.

Moreover, the great difference in the total percentage of comments related to "seeking input" between the L1 and L2 groups was caused by different ways of using the comment session. Although nearly half of the L1 and L2 groups sought help via commenting, the L1 groups mainly used the comment session to share resources, provide suggestion to improve the project and plan the project. This is consistent with Bradley's finding [14] that suggestion was the most frequent type of comment. In contrast, one L2 group used the comment session for topic discussion. They provided their own ideas and invited the input by other group members, commenting such as "that topic is good. How about the others? Do you have any suggestions?" (L2-G5-Stu C). This contributed to the higher percentage of "seeking input" comments in the L2 groups than in the L1 groups.

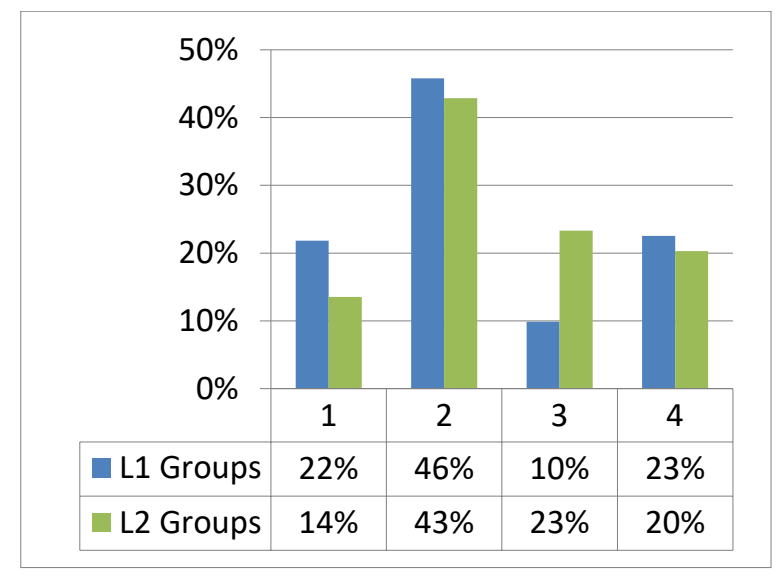

Fig.6. Distribution of Wiki Comments in the L1 and L2 Groups (1: planning, 2: contributing, 3: seeking input, 4: monitoring)

\section{Similarities and Differences in the Wiki Collaboration Level}

Both L1 and L2 groups showed low levels of collaboration among group members. The students in the two groups seldom reviewed the writing of other group members. As is illustrated in Figure 7, only 23\% and 22\% of wiki revisions were revised by a group member instead of the original author in the L1 and L2 groups respectively.

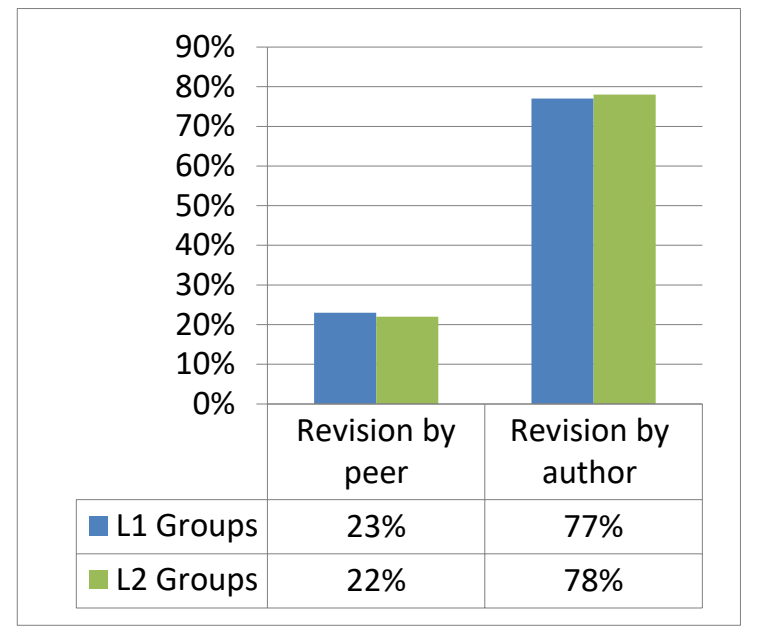

Fig.7. Total Percentage of Wiki Writing Revisions by Group Member and by Author in L1 and L2 Groups

The type of wiki revisions by other group members among the L1 and L2 groups are shown in Figure 8. Meaning developing and format change were the two most common changes performed by the L1 and L2 groups. These two types of revisions together formed $85 \%$ and $89 \%$ of the wiki revisions by group member in the L1 and L2 groups respectively.

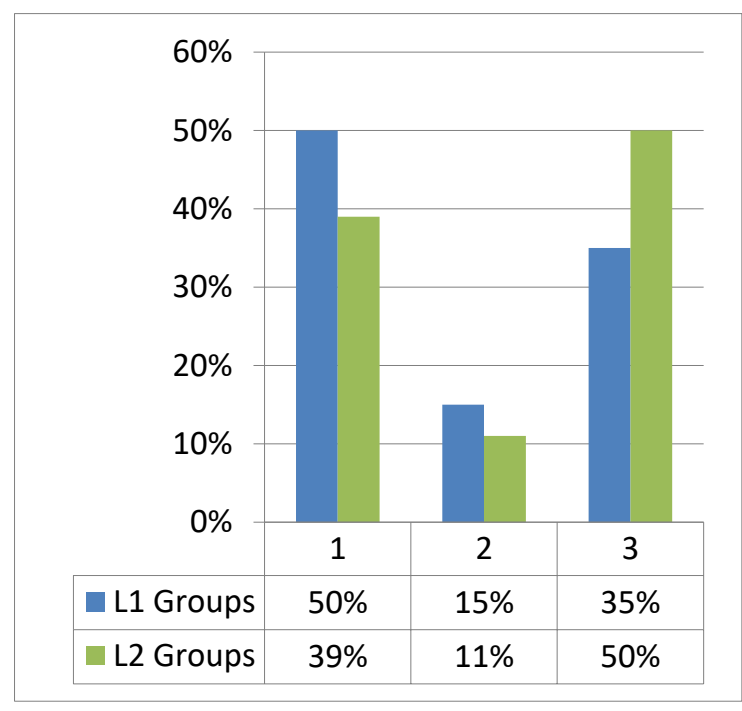

Fig.8. Distribution of Types of Wiki Revisions by Group Member in the L1 and L2 Groups (1: meaning developing change, 2: meaning preserving change, 3 : format change) 
Students' tendency to avoid editing other group members' writing may explain the low levels of collaboration found in the L1 and L2 groups. Mak and Coniam [7], who studied Hong Kong secondary student's wiki writing, reported similar findings. Liou and Lee [20] also suggested that students would rather revise their own writing than review other writers' writing as they thought they had to gain their approval first if they were to revise other writers' writing.

Although the L1 and L2 groups both showed low levels of collaboration, their revision patterns were different in that the L2 groups performed more format changes and less macrostructure meaning changes than the L1 groups. The difference in L1 and L2 language proficiency might explain the different patterns in the L1 and L2 groups. As the L2 groups lacked confidence in the second language, they might have focused on format changes and avoided making macrostructure changes to other group members' writing. In contrast, as the L1 students were familiar with their first language, they would be capable of making macrostructure changes to other writers' writing. Thus, the L2 groups made more format changes, while the L1 groups made more macrostructure changes when reviewing other group members' writings.

\section{E. Implications of the Study}

In this sub-section, we discuss four major implications of the finding in light of L1 and L2 writing in a wikibased environment. First, in terms of wiki collaborative writing activities, both L1 and L2 groups made only a small number of grammar edits. Similar to Storch's 2005 findings, a lack of language proficiency may have accounted for this practice in the $\mathrm{L} 2$ groups. We thus suggest that students, particularly L2 groups of students, take the opportunity of project work to learn how to write articles in the second language. We may draw some pedagogical implications. For example, Liberal Studies teachers and language teachers may adopt team-teaching [36] and co-design activities as an interdisciplinary project. They may consider providing necessary scaffolding, such as sentence openers and report structures, to facilitate students' wiki writing process. Teachers may also introduce the idea of plagiarism to students [37] as some groups did poorly in proper citation. Moreover, teachers may include the presentation of the wiki in their marking scheme to encourage students to explore features of the wiki such as embedding videos and creating subpages.

Second, despite its potential for participation as highlighted by Elgort, Smith, and Toland [38], participation and collaboration levels in both L1 and L2 groups were generally low. Moreover, students tended to make their contributions in the last few months before deadline. Judd, Kennedy, and Cropper [15] suggested that the key to success in wiki collaboration lies in its design and enactment of actitivities. The low participation level in this case may have resulted from a lack of time to plan and contribute the tasks. We may take possible measures to resolve these issues, such as breaking down project tasks, setting progressive milestones and phases for assignment submission. Furthermore, monthly meetings may be arranged for project progress reports. The low collaboration levels may also indicate students' reluctance to edit other group member's writing $[7,20]$. Pedagogical implications may include incorporating students' personal contribution into assessement to increase participation and setting peer revision as a task requirement to improve collaboration among students. Teachers may make it clear that collaboration and contribution are part of assessment and both the process and the products will be assessed [39]. It is also important that teachers provide suitable interventions in the learning process when necessary.

Third, we made some interesting observations on the wiki interaction shown in the use of comment sections. Both the L1 and L2 groups frequently used the comment sections to exchange information and to monitor progress The L1 groups also showed a greater use of the comment sections for planning purposes, while one L2 group used the comment function regularly as a platform for idea sharing and idea improvement, contributing to the higher percentage of "seeking input" comments in the L2 groups. Design implications and pedagogical implications may be drawn from this finding. Wiki is used as a space for cowriting and co-editing. However, it is inadequately designed for interaction between participants. The frequent use of comment sections by the L2 groups for "seeking input" and collaboration within group suggest that a space for group interaction needs to be provided, and that the comment function might have the potential to be used for this purpose. Teachers may encourage students to make better use of the comments function and use it as a space for collaboration, such as idea sharing, negotiation and idea improvement.

Finally, it was observed that none but one L2 group used the wiki platform for information sharing when interacting with one another. This finding supports Leung and Chu's study [12], in which other channels such as emails, phone calls or face to face meetings were used by students to communicate when writing on a wiki collaboratively. Similar finding was reported in Zorko [39] that participants had shown a preference to platforms other than wiki, for example, messenger, email and mobile devices. We thus suggest that teachers and researchers should take into consideration interactions that could have taken place on other platforms.

\section{CONCLUSION}

This study addresses the little discussed topic of the similarities and differences between wiki-based L1 and L2 writing and reports on a case study of a group of Hong Kong secondary school students engaged in a wiki-based Liberal Studies group project. The findings reveal similarities in wiki writing activity patterns, participation levels and collaboration levels, and differences in interaction patterns, with more comments on planning for the L1 groups and more comments related to seeking input for the L2 groups. The L2 groups were also found 
to conduct more revision concerning format changes on the wiki, and they seemed to avoid macrostructure changes such as meaning development. Implications are drawn to encourage a higher degree of, and more even participation and collaboration among students, particularly the L2 groups. A major limitation of this research was the small sample size. As there were only seven L2 groups in the current project, we only managed to include four L1 and four L2 groups for the purpose of comparison. Another limitation of the study was the type of data. It would have been more comprehensive if we had also included other data such as interviews or surveys to understand further the online activities. Future studies may scale up the current case study and include a larger sample size and more types of research data. Learning analytics, the "measurement, collection, analysis and reporting of data about learners and their contexts, for purposes of understanding and optimizing learning and the environments in which it occurs" (https://tekri.athabascau.ca/analytics/) as defined in the first International Conference on Learning Analytics and Knowledge in 2011, may also be adopted to facilitate future research. It would have the advantage of automating the process and saving the researchers from the current practice of manual counting. More importantly, it may enable the teachers to visualize the wiki interaction process, so that they may track the students' progress time by time and take necessary measures and interventions in the process.

\section{REFERENCES}

[1] D. D. Curtis, and M. J. Lawson, M.J. Exploring Collaborative Online Learning. The Journal of Asynchronous Learning Networks, Vol. 5(1), pp. 21-34, 2001.

[2] X. Li, S. K. W. Chu, and W.W Ki, The Effects of a Wikibased Collaborative Process Writing Pedagogy on Writing Ability and Writing Attitudes among Upper Primary School Students in Mainland China. Computers and Education, Vol. 77, pp. 151-169, 2014.

[3] H. Meishar-Tal, and P. Gorsky, Wikis: What Students Do and Do not Do when Writing Collaboratively. Open Learning, Vol. 25(1), pp. 25-35, 2010.

[4] A. Keen, Writing for publication: Pressures, Barriers and Support Strategies. Nurse Education Today, Vol. 27(5), pp. 382-388, 2007.

[5] M. Geraci, Implementing a Wiki as a Collaboration Tool for Group Projects. World Conference on Educational Multimedia, Hypermedia and Telecommunications, June 25-29, 2007, Vancouver, Canada.

[6] J. Rick, M. Guzdial, K. Carroll, L. Holloway-Attaway, and B. Walker, Collaborative Learning at Low Cost: CoWeb Use in English Composition. In: Proceedings of Conference on Computer Support for Collaborative Learning: Foundations for a CSCL Community, pp. 435442, 2002.

[7] B. Mak, and D. Coniam, Using Wikis to Enhance and Develop Writing Skills among Secondary School Students in Hong Kong. System, Vol. 36(3), pp. 437-455, 2008.

[8] N. Storch, Collaborative Writing: Product, Process, and Students' Reflections. Journal of Second Language Writing, Vol. 14(3), pp. 153-173, 2005.
[9] S. Wheeler, P. Yeomans, and D. Wheeler, The Good, the Bad and the Wiki: Evaluating Student-generated Content for Collaborative Learning. British Journal of Educational Technology, Vol. 39(6), pp. 987-995, 2008.

[10] M. Ebner, M., Kickmeier-rust, M. \& Holzinger, A. (2008). Utilizing wiki-systems in higher education classes: A chance for universal access? Universal Access in the Information Society, 7(4), 199-207.

[11] A. Ebersbach, M. Glaser, and R. Heigl, Wiki: Web Collaboration. Berlin: Springer-Verlag, 2006.

[12] K. Leung, and S. K. W. Chu, Using Wikis for Collaborative Learning: A Case Study of An Undergraduate Students' Group Project in Hong Kong. The International Conference on Knowledge Management, December 3-4, 2009, Hong Kong.

[13] J. Liu, and R.W. Sadler, The Effect and Affect of Peer Review in Electronic versus Traditional Modes on L2 Writing. Journal of English for Academic Purposes, Vol. 2, pp.193-227, 2003.

[14] L. Bradley, Peer Reviewing in an Intercultural Wiki Environment - Student Interaction and Reflections. Computers and Composition, Vol. 34, pp. 80-95, 2014.

[15] T. Judd, G. Kennedy, and S. Cropper, Using Wikis for Collaborative Learning: Assessing Collaboration through Contribution. Australasian Journal of Educational Technology, Vol. 26(3), pp. 341-354, 2010.

[16] G. Kessler, Student-initiated Attention to Form in Wikibased Collaborative Writing. Language Learning and Technology, Vol. 13(1), pp. 79-95, 2009.

[17] M. Kuteeva, Wikis and Academic Writing: Changing the Writer-reader Relationship. English for Specific Purposes, Vol. 20, pp. 44-57, 2011.

[18] M. Guardardo, and L. Shi, ESL Students' Experiences of Online Peer Feedback. Computers and Composition, Vol. 24(4), pp. 443-461, 2007.

[19] R. Shaw, A Study of the Relationships among Learning Styles, Participation Types and Performance in Programming Language Learning supported by Online Forums. Computers \& Education, Vol. 58, pp. 111-120, 2012.

[20] H. C. Liou, and S. L Lee, How Wiki-based Writing Influences College Students' Collaborative and Individual Composing Products, Processes, and Learners' Perceptions. International Journal of Computer-Assisted Language Learning and Teaching (IJCALLT), Vol. 1(1), pp. 45-61, 2011.

[21] T. Silva, Toward an Understanding of the Distinct Nature of L2 Writing: The ESL Research and its Implications. Tesol Quarterly, Vol. 27 (4), pp. 657-677, 1993.

[22] J. R. Larios, and L. Murphy, A Temporal Analysis of Formulation Processes in L1 and L2 Writing. Language Learning, Vol. 51(3), pp. 497-538, 2001.

[23] T. Takagaki, The Revision Patterns and Intentions in L1 and L2 by Japanese Writers: A Case Study. TESL Canada Journal, Vol. 21(1), pp. 22-38, 2003.

[24] X. H. Liu, and C. Furneaux, A Multidimensional Comparison of Discourse Organization in English and Chinese University Students' Argumentative Writing. International Journal of Applied Linguistics, Vol. 24 (1), pp. 74-96, 2014.

[25] A. F. Dobao, Collaborative Writing Tasks in the L2 Classroom: Comparing Group, Pair, and Individual Work. Journal of Second Language Writing, Vol. 21(1), pp. 40$58,2012$.

[26] A. Shehadeh, Non-native Speakers' Production of Modified Comprehensible Output and Second Language 
Learning. Language learning, Vol. 49(4), pp. 627-675, 1999.

[27] M. M. Woo, S. K. W. Chu, and X. Li, Peer-Feedback and Revision Process in a Wiki Mediated Collaborative Writing. Educational Technology Research and Development, Vol. 61(2), 279-309, 2013.

[28] R. K. Yin, Case Study Research: Design and methods, Fifth Edit. Thousand Oaks, CA: Sage Publications. R. K., 2014.

[29] S. B. Merriam, Qualitative Research and Case Study Applications in Education. Revised and expanded from" Case Study Research in education". San Francisco, CA: Jossey-Bass. S. B., 1998.

[30] C. Adelman, D. Jenkins, and S. Kemmis, Re-thinking Case Study: Notes from the Second Cambridge Conference. Cambridge Journal of Education, Vol. 6(3), pp. 139-150, 1976.

[31] D. Nunan, Research Methods in Language Learning. Cambridge University Press, 1992.

[32] P. Duff, Development in the Case Study Approach to SLA Research. In: Proceedings of the First Conference on Second Language Acquisition and Teaching, pp. 34-87, 1990.

[33] U. Pfeil, P. Zaphiris, and C. S. Ang, Cultural Differences in Collaborative Authoring of Wikipedia. Journal of Computer-Mediated Communication, Vol. 12(1), pp. 88113., 2006.

[34] N. Arnold, L. Ducate, and C. Kost, Collaborative Writing in Wikis: Insights from Culture Projects in German Classes, in The Next Generation: Social Networking and Online Collaboration in Foreign Language Learning, L. Lornicka, and G. Lord, Eds., pp. 115-144. San Marcos, TX: CALICO. C., 2009.

[35] M. B. Miles, and A. M. Huberman, An Expanded Sourcebook Qualitative Data Analysis, Second Edit. California: Sage Publications., 1994.

[36] F. Pawan, and J. H. Ortloff, J. H, Sustaining Collaboration: English-as-a-second-language, and Content-area Teachers. Teaching and Teacher Education, Vol. 27(2), pp. 463-471, 2011.

[37] S. Hadjerrouit, Investigating Technical and Pedagogical Usability Issues of Collaborative Learning with Wikis. Informatics in Education-An International Journal, Vol. 11(1), pp. 45-64. 2012.

[38] I. Elgort, A. G. Smith, and J. Toland, Is Wiki an Effective Platform for Group Course Work? Australasian Journal of Educational Technology, Vol. 24(2), pp. 195-210, 2008.

[39] V. Zorko, Factors Affecting the Way Students Collaborate in a Wiki for English Language Learning. Australasian Journal of Educational Technology, Vol. 25(5), pp. 645665, 2009.

\section{Authors' Profiles}

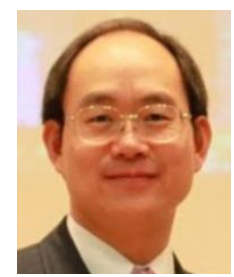

Dr. Samuel K. W. Chu works as Associate Professor in the Division of Information and Technology Studie, Faculty of Education, the University of Hong Kong. His areas of expertise include: Game-based Learning, Gamification in Education, 21st Century Skills, Social Media in Education, Plagiarism-free Collaborative Inquiry Project-based Learning, Knowledge Management

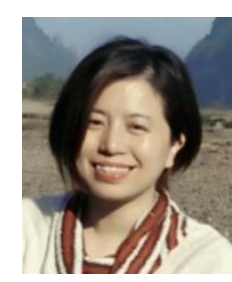

Jing Wu is currently pursuing Ph.D. in Education in National Institute of Education, Nanyang Technological University, Singapore. She is specialized in new media and learning. Her research topic is on developing criticality in students with digital storytelling approach in character education context.

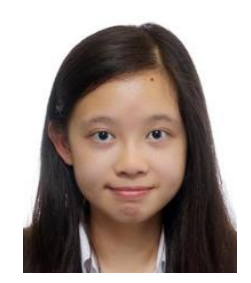

Crystal W. S. Kwan obtained her Bachelor's degree in English studies from City University of Hong Kong with first class honors. Currently, she is studying a postgraduate diploma in English (Secondary education) at the Education University of Hong Kong. Her interests are pedagogy

and English language education.

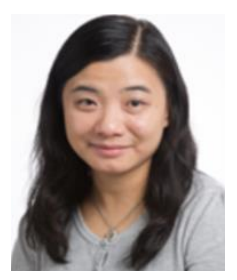

Dr. Jean H.Y. Lai is a lecturer in the Department of Computer Science at the Hong Kong Baptist University. She obtained her $\mathrm{PhD}$ degree from the City University of Hong Kong. Her research interests cover the areas of technology use in education, social computing, and decision making in finance.

How to cite this paper: Samuel K. W. Chu, Jing Wu, Crystal W. S. Kwan, Jean H. Y. Lai, "Wiki-based Collaborative Writing: A Comparative Study on First and Second Language Writing among Chinese Secondary Students", International Journal of Modern Education and Computer Science(IJMECS), Vol.11, No.1, pp. 1-10, 2019.DOI: 10.5815/ijmecs.2019.01.01 